\title{
The Rhetoric Of Action Description: Ambiguity In Intentional Reference
}

\author{
Randal Marlin
}

Carleton University

I propose to describe and analyse a common, powerful and frequently effective rhetorical device that has hitherto escaped adequate notice.1

As a first approximation, we may call it the Ambiguous Action Description, but this term is too broad to capture the specific character of the tool in question. The name capturing the specificity will probably baffle readers on first encounter, and will require explanation. It is "Translucency of Intentional Reference in Action Description," or "Referential Translucency" for short.

This name is suggested by comparison with two terms that have gained currency with Quine's influential article, "Reference and Modality."2 The terms are "referential opacity" and "referential transparency." A brief explanation of these terms will be provided for the sake of readers not already familiar with them. The observation has been made that in the context of statements involving intentionality or modality (we need not concern ourselves here with the latter) the replacement of one description by another having identical reference cannot always be made while preserving the truth of the statement. So, to use the frequently cited example, the statement "John knew that Cicero denounced Catiline" cannot be re-stated as "John knew that Tully denounced Catiline" while preserving the same truth, even though Tully and Cicero were the same person. For John might not have known that Cicero was the same as Tully. In such intentional, or opaque, contexts, one cannot freely substitute different names or descriptions of identical persons or objects if one is to preserve truth values.
By contrast, in referentially transparent contexts different descriptions or names of an identical referent can be freely substituted. The statements "Voltaire wrote Candide" and "Voltaire was Arouet" together imply "Arouet wrote Candide." If "Antony passed by Cicero" is true, then in conjunction with "Cicero was Tully" it follows that "Antony passed by Tully" is true. So long as Cicero and Tully are one and the same person, the truth of the former statement guarantees the truth of the latter.

Now, not all contexts are clearly one or the other, that is to say referentially transparent or opaque. Substitute "saw" for "passed by" in the above statement and we may feel substitutivity becoming problematic. Some verbs are ambiguous as to the extent of intentionality implied. A good example is the verb "help". When we say that "Jones helped bring about the Progressive Party's defeat," we may think of this either as a case where Jones acted with the Intention of bringing about the Progressive Party's defeat, or as a case where Jones may have intended nothing of the kind, perhaps may have been working to avoid the defeat, but in ways that, as things turned out, were counter-productive. The verb "help" in this context is what I choose to call clearly opaque nor clearly transparent. We could of course say that the word is merely ambiguous, but the new term fixes in our minds the specific kind of ambiguity which is in question.

A skillful propagandist can exploit this kind of ambiguity. The idea that the Partido Obrero the Unificación Marxista (POUM) and the Anarchists were "objectively Fascists" and that they were "assist- 
ing" the Fascists was promoted by the Communist press during the Spanish Civil War. According to Ceorge Orwell, neither the POUM nor the Anarchists were agents of the Fascists and allegations to that effect were false: both were as much opposed to Fascists as were the Communists.4 But quite apart from the truth of claims as to deliberate connivance, there was the undeniable fact that the rift between the Communists on the one hand and the POUM and Anarchists on the other was indeed assisting Franco. So it was good, or effective, rhetoric to insist that the POUM (tendentiously known as Trotskyists) were "helping," "assisting" (or some similar word the Fascists. Using the terminology I have proposed, we may say that when the verb "helping" is used transparently; there was no denying the truth of Communist charges. The POUM did indeed help the Fascists, though Orwell says they had no such intention. But to the extent that their intention to help Fascists was absent, one basis for severe condemnation of them among the Left was removed. 5 Used opaquely, that is to say with the implication that the POUM intended to help the Fascists, the charge might be denied. But if the charge were true it would indeed be a sound basis for extreme condemnation of the POUM among the Left. Used translucently, that is to say without making clear whether "helping" or similar terms are to be taken as implying intention on the part of persons referred to, the expressions draw support for their truth from the former (transparent) interpretation and the power of condemnation from the latter (opaque) interpretation.

Before considering some more examples of the device I am describing, it may be helpful to clarify the terminology $I$ am employing. How is it, for example, that the terms "referential opacity" and "referential transparency" -originally used in the context of names and descriptions - have come to be applied verbs? The answer is that logicians have been concerned with statements involving two components. The statements involve a reference to some person and a reference to some mental content of that person. The logicians observed that you cannot, while always preserving truth, subsitute different names or descriptions referring to identical things so long as the substitution takes place within the part describing the mental content of the person. "John saw Harrison" need not have the same truth value as "John saw the escaped prisoner" even when Harrison and the escaped prisoner are the very same individual, so long as John did not know that the two were identical. My analysis, however, is from the standpoint of rhetoric and involves four components. First, there is the rhetorician, or communicator. Second, there is some person, or party, or group referred to-whatever, in short, possesses a mind. Third, there is the action or mental state attributed by the rhetorician to the person. Fourth, there are consequences of the person's action, or circumstances, or other objects of the person's mental states that are referred to. The rhetorician may use action verbs or mental state descriptions which signal that the truth values of assertions about consequences, etc., are to be understood opaquely, that is to say in the light of the understanding, intention, etc., of the person referred to. Or, the verbs or mental state descriptions may be such as to signal that the truth values are to be understood transparently, that is to say objectively, not dependent on the understanding of the person referred to.

As an example, suppose we have a reporter, and a news story about a man who shot his wife thinking she was a bear. The reporter writes: "Jones carefully aimed his gun at his target, shot and killed his wife." The statement is true if, in the terminology I have proposed, it is to be understood transparently. It is false if used opaquely. The statement which would be true opaquely is: "Jones carefully aimed his gun at his target, shot and killed the 'bear'." Clearly, in this kind of situation, common sense rapidly pulls us out of the opaque context, and we re-enter it only for the purpose of establishing such things as the extent of blame attributable to an accused Jones. The example suggests to me that more often than not the verbs we use in such descriptions are translucent, that we hesitate to say categorically that either of the statements is true or false, but wish to qualify them appropriately. And just because in many cases the appropriate qualification is not sought or available, the carefully chosen use of translucent expression can be ever so valuable for the propagandist. I turn now to some actual examles.

A recent example can be found in the Toronto Globe and Mail, January 26, 1984. Before describing the example, however, I want to point out that false impressions are not always conveyed deliberately. Study of "referential translucency" can help us recognize communications that mislead without the communicator necessarily being aware, or fully aware, of the fact. The example is a headline on page one, which stated: "Nazis fled after war with help of Vatican, U.S. document reveals." The headline will have suggested to many readers, without clearly asserting, that the Vatican knowingly helped Nazis escape, event though there was no good evidence in the story itself that the relevant knowledge was present. On the contrary, the story quoted Rev. Antonio Weber, who headed the Vatican's organization for emigration aid, Opera San Rafaele, during the Second World War, as saying that his office had helped many people, including about 20,000 Jews fleeing Hitler, without in many cases knowing their real identities. "We didn't know if they were or weren't war criminals," Father Weber was quoted as saying. "Even if these war criminals came with their real names, who knew at the time they were war criminals?" Now common sense tells us that under the circumstances it is very likely the Vatican would have assisted some Nazis without knowing 
they were Nazis. The important question is that of knowledge and the story provided no good evidence on that point. Without such evidence the story's headline conveys, through referential translucency, an unfavourable impression of the Vatican that the story itself doesn't warrant. 6

The same newspaper provided another example on May 24, with the headline boxed on the summary column of page one: "Pope Fouls Up Bar Mitzvah." The story related to the change of plans for a bar mitzvah necessitated by the large crowds anticipated in the area of the Synagogue by reason of the Pope's visit. Obviously, the Pope intended no such problem by his visit, even though it would have been a foreseeable outcome of such a visit that many changes in plans would have to be made in the light of anticipatable crowds. To fix on one such plan, treating it in isolation from the general set of problems and describing the Pope's relation to it by the referentially translucent verb "to foul up", encourages the belief that the Pope somehow is malevolently disposed towards bar matzvahs - if not in general, then this one in particular. Stated explicitly, the idea is absurd. But it is the essence of a very effective form of propaganda that it does not state explicitly what it wishes the hearer to believe, but communicates, as indicated earlier, by suggestion .7

Different verbs seem to fit into different places on a continuum between referentially opaque contexts and those that are referentially transparent. For example, "James defaulted, so that John lost," does not imply, though it may barely suggest, that James intended to ensure John's losing. If we want to avoid any such suggestion, we can say "James defaulted without intending that John should lose." If there was such an intention, we can make this clear by saying "James defaulted with the aim of bringing about John's losing, and he succeeded." But in between these extremes we have verbs of greater or less ambiguity, veering to one side or the other of the scale. To say "James helped John lose" suggests to some extent the presence of the intention to bring about the stated consequence. The suggestion seems to me stronger (not every reader may feel this way) when we use such verbs as "brought about" John's loss, or "ensured" John's defeat, or suchlike. It seems strongest when we use a term such as "engineered." One hardly "engineers" a defeat without intending that result. The exception might be of the following sort: James engineers a complicated course of action for another purpose, which happens to result in John's defeat, although John's defeat was no part of the plan. One might be tempted to say, misleadingly, that "James engineered John's loss."

Let us call verbs that impute a degree of an intention to the doer, in relation to some consequence, "intention-promoting." The use of intention-promoting words can raise the level of alleged culpabil- ity of an agent in relation to some consequence from that of inadvertence, to negligence, to recklessness, and finally to maximum culpability. "A caused B's death" is less intention-promoting than "A killed $B$ " and both are less intention-promoting than " $A$ murdered B."

A skillful rhetorician can made use of verbs and adverbs with just the desired ambiguity to conceal or reveal as much as he, or she, wants to conceal or reveal.

It is worth adding a word to make clear that intention not only as to consequences, but also as to circumstances, may play an important part in ambiguities of action description. Usually, a change in knowledge of circumstances that morally affects an action will also be reflected in the consequences of the action, but not always, or at least not for moralists of Kantian bent.

I have concentrated here on ambiguity in choice of verbs, but similar considerations apply to choice of nouns reflecting relevant verbs and intentions. Take the case of Oedipus. Oedipus killed the stranger, not knowing that the stranger was his father. The rhetorician who wanted to bring Oedipus into disrepute could make use of the translucency of the intention-promoting noun "parricide," as in "Oedipus was guilty of parricide." The word suggests, what is false, that Oedipus intended to kill his father; but there is perhaps a slender margin of ambiguity and the rhetorician can fall back on: "Well, he did kill his father, didn't he?" using a less intentionpromoting term. We see through the ruse, but perhaps not everybody does. And in cases of more subtle referential translucency the likelihood of our being deceived is greatly increased, unless we are on guard against this device in advance. 8.9

\section{Notes}

'Eric D'Arcy's Human Acts (Oxford, 1963), to which I am indebted, dealt mainly with moral rather than rhetorical aspects. Logical aspects of related matters are dealt with in e.g. Elizabeth Anscombe's "Under a Description." Nous, 13 (1979).

2W.V.O. Quine, From a Logical Point of View, (Harvard, 1961.)

"The "was" being one of identity. Qualification is needed. We cannot, for example, freely substitute pseudonyms with coded meanings. Johannes de Silentio did not write Concluding Unscientific Postcript, even though both de Silentio and Johannes Climacus, the stated author, were pseudonyms of Kierkegaard.

4 See George Orwell, Homage to Catalonia (London: Penguin, 1979.) Most pertinent is page 63 , but pp. 139, 143, 153-4 and 165 provide more details. 
See also Bernard Crick, George Orwell: A life, Penguin, 1980, p. 332.

5 It is quite possible, though, to charge the POUM with negligence, recklessness or the like. If they were ignorant of the likely effects of their dessent from the Communists they were perhaps culpably ignorant. But that is still very different from aiming to support the Fascists.

6 I would not want to claim that the Toronto Globe and Mail was deliberately trying to manipulate opinion against the Catholic Church. That is not to say the paper was without fault, though. The New York Times, January 26, 1984 headlined the same story "Vatican is Reported to Have Furnished Aid to Fleeing Nazis," which at least withholds the newspaper's endorsement of the report. To say the report "reveals," as the Globe did, conveys that the Globe believes the report is true.

For a report that the Vatican was unwillingly duped by U.S. Intelligence agencies after World War II, see the Citizen, Ottawa, February 25, 1984, p. 20. The report from UPI in Boston, quotes John Loftus, former Justice Department prosecutor as saying that Vatican officials were told the people they were helping to evacuate were antiCommunist refugees.

7 Once again, it seems unlikely that the Globe was deliberately trying to stir up antagonism between Catholics and Jews. But given enough examples, one can make a good case for at least some unconscious bias operating. The accusation that someone has made use of "referential translucency" is itself an accusation that is referentially translucent, in that it does not spell out whether the person referred to deliberately intended to deceive by means of it. I believe it is more useful to be able to apply the term to ambiguities which creep in unconsciously as well as those which are deliberately planned, than it would be to restrict the terms to the latter cases only.

${ }^{8}$ As I have characterized the term "referential translucency" it arises in the context of some communicator reporting on another person's action or mental state with regard to some consequences, circumstances or suchlike. But in a courtroom setting the communicator can make use of this ambiguity in the form of questions, so that a witness is led into the role of the communicator, communicating about himself and his previous acts or mental states in relation to some objects, in ways that distort the truth. The witness will seem to have special authority about his own acts or mental states, but this seeming authority will be specious if the witness is befuddled by the ambiguity I have described.

I can give an example from personal experience Our community association was fighting (unsuccessfully, as it turned out) a proposed seat expansion to Lansdowne Park Stadium, which is in our area. We had presented a petition of 2,000 signatures opposing the expansion to the Ontario
Municipal Board. The grapevine had alerted me to the fact that the Ottawa Rough Riders (a team in the professional Canadian Football League) had sent an opposing petition to all Rough Riders season ticket subcribers. In the witness box during the $\mathrm{OMB}$ hearing I was asked by the rough Riders' lawyer: "Are you aware that there was another petition that obtained 8,000 signatures in favour of the seat expansion?" If I answered "Yes" I would have appeared to be confirming numbers that I had no knowledge of, and discrediting my own petition to boot so far as numbers were concerned. If I answered "No" I would merely have seemed factually ignorant, or perhaps suppressing knowledge of a petition whose existence I did not wish to face. I replied: "I am aware of another petition that was sent to all Rough Riders' season ticket subscribers. I do not know whether that petition was one and the same petition as a petition that got 8,000 signatures." The answer conveyed my state of mind accurately, while also helping somewhat to suggest a bias in the opposing petition. But it was hard on the spot to convey my state of mind accurately. Since my response benefitted from training in questions of intentionality, it makes one wonder how someone not so trained would have responded to the question. The use of translucent expressions, as I have called them, can readily lead a witness down the path of false or misleading testimony. For this reason, among others, there are cases where a fair-minded judge should simply disallow the constraint that lawyers sometimes force upon reluctant witnesses, namely to answer "Yes" or "No" and nothing else.

In another courtroom case, a U.S. obscenity trial, an English or literature professor was somewhat discredited as an experts witness because he did not recognize the name of that famous author and thinker of the Enlightenment, François Marie Arouet. Without knowing that Arouet wrote under the pen name Voltaire, the witness was unable to identify Arouet as the author of the famous works we all know, such as Candide. It is unpardonable not to know of Voltaire (in educated circles), but it is no mark of illiteracy not to know that Voltaire was Arouet. Unfortunately I have been unable to re-locate the reference to this exchange.

9 wish to thank the editors of this journal for helpful suggestions, and many colleagues at Carleton University for useful comments-in particular Peter Bruck, and Stephen Talmage. Thanks also to Danny Goldstick for a comment which led to my inclusion of footnote 5 , and to Hilda van Stockum and my wife Elaine for useful stylistic comments

Randal Marlin, Department of Philosophy, Carleton University, Ottawa, Ontario, Canada, K1S 5 B6 